\title{
Implementation of Flow Tripping Capability in the USM3D Unstructured Flow Solver
}

\author{
Mohagna J. Pandya* \\ Analytical Services \& Materials, Inc, Hampton, Virginia 23681, USA \\ Khaled S. Abdol-Hamid ${ }^{\dagger}$, Richard L. Campbell ${ }^{\dagger}$, and Neal T. Frink ${ }^{\dagger}$ \\ NASA Langley Research Center, Hampton, Virginia, 23681, USA
}

\begin{abstract}
A flow tripping capability is added to an established NASA tetrahedral unstructured parallel Navier-Stokes flow solver, USM3D. The capability is based on prescribing an appropriate profile of turbulence model variables to energize the boundary layer in a plane normal to a specified trip region on the body surface. We demonstrate this approach using the k- $\varepsilon$ two-equation turbulence model of USM3D. Modification to the solution procedure primarily consists of developing a data structure to identify all unstructured tetrahedral grid cells located in the plane normal to a specified surface trip region and computing a function based on the mean flow solution to specify the modified profile of the turbulence model variables. We leverage this data structure and also show an adjunct approach that is based on enforcing a laminar flow condition on the otherwise fully turbulent flow solution in userspecified region. The latter approach is applied for the solutions obtained using other oneand two-equation turbulence models of USM3D. A key ingredient of the present capability is the use of a graphical user-interface tool PREDISC to define a trip region on the body surface in an existing grid. Verification of the present modifications is demonstrated on three cases, namely, a flat plate, the RAE2822 airfoil, and the DLR F6 wing-fuselage configuration.
\end{abstract}

\section{Nomenclature}

$a \quad=$ speed of sound

$C_{L} \quad=$ lift coefficient

$C_{D} \quad=$ total drag coefficient

$C_{D v} \quad=$ viscous drag coefficient

$\mathrm{C}_{f} \quad=$ local skin friction coefficient

$C_{p} \quad=$ pressure coefficient

$\mathrm{c} \quad=$ chord

$k \quad=$ turbulent kinetic energy

$k^{*} \quad=$ normalized turbulent kinetic energy of freestream, $k^{*}=k / a_{\infty}$

$M_{t} \quad=$ turbulent Mach number

$M_{\infty} \quad=$ freestream Mach number

$R e_{c} \quad=$ Reynolds number based on a reference chord

$R e_{x}=$ local Reynolds number at axial station, $x$

$u_{i} \quad=$ velocity components in $x, y, z$ directions

$u^{+}, y^{+} \quad=$ law-of-wall coordinates

$x, y, z=$ spatial coordinates

${ }^{*}$ Senior Scientist, Mail Stop 499, NASA Langley Research Center, AIAA Senior Member.

${ }^{\dagger}$ Senior Research Engineer, Configuration Aerodynamics Branch, Mail Stop 499, AIAA Associate Fellow. 


$\begin{array}{ll}\alpha & =\text { angle-of-attack } \\ \varepsilon & =\text { turbulent energy dissipation } \\ \mu_{l} & =\text { dynamic laminar viscosity } \\ \mu_{t} & =\text { dynamic turbulent viscosity of freestream } \\ \mu_{t}^{*} & =\text { normalized dynamic turbulent viscosity of freestream, } \mu_{t}^{*}=\mu_{t /} \mu_{l}\end{array}$

\section{Introduction}

Computational fluid dynamics (CFD) codes have become an essential tool for the analysis of aerodynamic configurations. During the last two decades, flow solvers and computer hardware have been advanced to a level that allows for efficient computational simulation of complex configurations. However, these simulations are primarily targeted toward steady-state flow applications using the Reynolds Averaged Navier-Stokes (RANS) equations. Many of these RANS solvers, especially those in the unstructured grid arena, continue to use one-equation turbulence models for capturing the turbulence effect on the mean flow. On the other hand, for wide range of engineering problems a turbulence model should be capable of providing a time scale and a consistent description of the production and transport properties of turbulent kinetic energy. Therefore, it is necessary to enhance the capabilities of current RANS codes by incorporating at least a two-equation turbulence closure model.

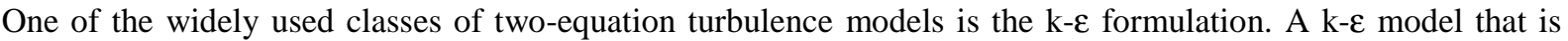
applicable in the near-wall region as well as in the regions far away from the wall boundary is typically used. In the flow regions far away from the solid boundary, a high Reynolds number form of the model can be used. Several different low Reynolds number formulations of k- $\varepsilon$ model have been proposed for the near-wall region. In general, low Reynolds number k- $\varepsilon$ turbulence models suffer from one major drawback in flow applications containing solid surfaces. Numerical simulations based on these low-Reynolds number $k-\varepsilon$ models tend to depend on the prescribed far-field turbulence value, grid resolution, and the dissipation level inherent in a numerical scheme. These solutions contain varying sizes of laminar regions. Rumsey et al. [1] showed that by applying a Nullcline analysis to the k$\varepsilon$ equation set, it is possible to clearly demonstrate the reasons for this anomalous behavior.

The present study extensively uses the k- $\varepsilon$ model. Therefore, we will first assess the well known anomalous characteristic of the model considering its USM3D-specific implementation. We will show that the k- $\varepsilon$ based USM3D solutions also depend on the far-field turbulence and grid resolution. We seek to overcome this deficiency by implementing a tripping mechanism that energizes the boundary layer in a plane normal to the specified surface trip region. The approach is based on the assumption that in the flow transition region, the turbulence production equals its dissipation. We will show that by using this approach, the dependence of flow solutions on the free stream turbulence is completely eliminated. The method can also be utilized to more closely match the experiments conducted with transition strips. The present tripping approach is successfully used in structured grid CFD solver PAB3D for the last 15 years. The USM3D implementation of this method is verified on three test cases, namely, a flat plate, the RAE 2822 airfoil, and the DLR F6 wing-fuselage configuration. By leveraging a data structure developed for the flow tripping approach, we will also show preliminary computations in which a laminar flow solution is prescribed in a user-specified region.

\section{II. $\square$ Description of Methodology}

The NASA Tetrahedral Unstructured Software System (TetrUSS) [2] is a complete flow analysis system that has been widely used in industry and government since 1991. Its strength is derived from harnessing various component technologies into a user-friendly system to provide rapid, higher-order analysis and design capability to the applied aerodynamicists. It consists of loosely integrated, user-friendly software that comprises a geometry setup tool GridTool [3], a tetrahedral grid generator VGRID [4], [5], a flow solver USM3D [6], [7] and several post-processing visualization and data extraction utilities. The extensions addressed in this paper pertain to the USM3D flow solver and will be described below.

\section{A. USM3D Flow Solver}

USM3D [6], [7] is a tetrahedral cell-centered, finite volume Euler and Navier-Stokes (N-S) flow solver. Inviscid flux quantities are computed across each cell face using Roe's [8] flux-difference splitting (FDS). Spatial discretization is accomplished by a novel reconstruction process [9], based on an analytical formulation for computing solution gradients within tetrahedral cells. The solution is advanced to a steady state condition by an implicit backward-Euler time-stepping scheme [10]. 
USM3D has several models for capturing flow turbulence effects. First is the Spalart-Allmaras (SA) oneequation model [11], which can be coupled with a wall function boundary condition to reduce the number of cells in the sublayer region of the boundary layer. However, the wall function is typically only used when extensive curvature-based separation is not expected in a flow simulation. The second model is the two-equation $\mathrm{k}-\varepsilon$ turbulence model [12], [13]. The third model is the Menter SST two-equation model [14]. These turbulence models have undergone rigorous testing on propulsion afterbody flows in reference [15]. In addition, nonlinear Algebraic Reynolds Stress Model (ARSM) proposed by Girimaji [16] and Shih et al. [17] have been installed in USM3D recently, and they are undergoing verification testing.

USM3D supports an array of useful boundary conditions (BCs). It contains the standard BCs of flow tangency or no-slip on solid surfaces, characteristic inflow/outflow for subsonic boundaries, and freestream inflow and extrapolation outflow for supersonic flow. It also contains some additional special BCs for jet exhaust and intake, a propeller/rotor actuator disk model, and passive porosity [18]. The most recent enhancements to USM3D are second-order time accuracy, Detached-Eddy Simulation capability and dynamic grid motion [19] and overset-grid moving body capability [20].

The USM3D runs on massively parallel computers and clusters of personal computers (PC's). A grid partitioning file is quickly generated during a preprocessing step. A global restart file is generated and saved during and after each run.

\section{B. Data Structure for Flow Tripping}

The boundary-layer tripping capability is implemented in USM3D by assigning a new boundary condition to the grid triangles on a given surface patch or set of patches. This initially required the user to regenerate the grid with these patches explicitly defined for each trip location desired using GridTool. An alternate approach has been developed that utilizes the PREDISC code to define the tripping location using the original grid.

PREDISC is a graphical user interface that was developed to assist in the setting up of design cases using the CDISC design method and to allow rapid evaluation of design or analysis results [21]. To specify a trip location on a given component, the user defines the span wise endpoints of the leading edge of the trip zone, along with a stream wise width of the zone. These locations may be manually entered or graphically selected using the surface grid points. PREDISC provides a visual check of the surface triangles that are included in the zone, and the parameters can be easily adjusted to get the desired zone shape (there is also an option for adding or deleting individual triangles if needed). Multiple segments may be defined on a component to correspond to the lay out of transition strips on a wind tunnel model.

After all the tripping zones are set up, PREDISC extracts the corresponding surface triangles, assigns them to new patches, and saves new grid files (TetrUSS files, .mapbc, .bc, and iface) that are consistent with these new definitions. In addition to the definition of tripping zones, this capability could be useful in applications involving flow control, where zones or individual triangles may require blowing, suction or passive porosity boundary conditions. Figure 1 displays various trip patches on the DLR F6 fuselage and upper as well as lower wing surfaces that are defined using PREDISC by extracting an appropriate set of surface triangles from the existing unstructured tetrahedral grid for this configuration.

In a solution pre-processing step, USM3D identifies all tetrahedral cells that are located in a plane normal to the user-specified surface trip patches. The identification of such cells in an unstructured grid is presently accomplished by using a cell-to-surface-triangle mapping that associates each tetrahedral cell to the nearest triangle on the body surface. The mapping is read from the TetrUSS iface file. Figure 2 provides a schematic view of the tetrahedral cells that are associated with the upper and lower wing surface trip patches for the DLR F6 wing-fuselage configuration.

\section{Modification to Turbulence Model Variables for Flow Tripping}

The flow tripping mechanism has been developed in the context of two-equation $k-\varepsilon$ turbulence model following the work of Carlson [22] using the PAB3D [23] structured grid flow solver. This approach is presented below.

\section{Governing Equations}

The governing equations solved in this study are the Reynolds Averaged Navier-Stokes (RANS) equations. The perfect gas law is chosen to represent air properties. The conservative form of the time-averaged mass, momentum, and energy conservation equations can be written as follows: 


$$
\begin{aligned}
& \frac{\partial \rho}{\partial t}+\frac{\partial \rho u_{i}}{\partial x_{i}}=0 \\
& \frac{\partial \rho u_{i}}{\partial t}+\frac{\partial\left(\rho u_{i} u_{j}+p \delta_{i j}\right)}{\partial x_{j}}=\frac{\partial\left(\tau_{i j}-\rho \overline{u_{i} u_{j}}\right)}{\partial x_{j}} \\
& \frac{\partial \rho e_{0}}{\partial t}+\frac{\partial\left(\rho e_{0} u_{i}+p u_{i}\right)}{\partial x_{i}}=\frac{\partial\left(\tau_{i j} u_{j}-\rho \overline{u_{i} u_{j}} u_{j}\right)}{\partial x_{i}}-\frac{\partial\left(\rho\left(\frac{v}{P r}+\frac{v_{t}}{P r_{t}}\right) \frac{\partial h}{\partial x_{i}}\right)}{\partial x_{i}}
\end{aligned}
$$

Three k- $\varepsilon$ turbulence models are implemented in USM3D to model flow turbulence; standard k- $\varepsilon$ model [12] and two algebraic stress models of Girimaji [16] and Shih-Zhu-Lumley [17]. The algebraic stress models give inherently better results than the linear stress model because of the explicit modeling of relaxation and the nonlinear anisotropic effects using the mean flow strain and vorticity. With a nonlinear model, the calculation of six independent, realizable Reynolds stress terms is possible. This type of detail is important for simulating complicated multidimensional flows. In the k- $\varepsilon$ two-equation turbulence model, the eddy-viscosity concept is used to model the Reynolds stresses. The model equations are as shown below.

$$
\begin{aligned}
& \frac{\partial \rho k}{\partial t}+\frac{\partial \rho u_{i} k}{\partial x_{i}}=-\rho \overline{u_{i} u_{j}} \frac{\partial u_{j}}{\partial x_{i}}+\frac{\partial}{\partial x_{i}}\left[\rho\left(v_{l}+\frac{c_{\mu} k^{2}}{\sigma_{k} \varepsilon}\right) \frac{\partial k}{\partial x_{i}}\right]-\rho \varepsilon \\
& \frac{\partial \rho \varepsilon}{\partial t}+\frac{\partial \rho u_{i} \varepsilon}{\partial x_{i}}=-C_{\varepsilon 1} \rho \overline{u_{i} u_{j}} \frac{\partial u_{j}}{\partial x_{i}} \frac{\varepsilon}{k}+\frac{\partial}{\partial x_{i}}\left[\rho\left(v_{l}+\frac{c_{\mu} k^{2}}{\sigma_{\varepsilon} \varepsilon}\right) \frac{\partial \varepsilon}{\partial x_{i}}\right]-f_{2} C_{\varepsilon 2} \rho \frac{\varepsilon}{k}\left[\varepsilon-2 v_{l}\left(\frac{\partial \sqrt{k}}{\partial n}\right)^{2}\right]
\end{aligned}
$$

Where,

$$
\begin{aligned}
& C_{\mu}=0.09, \quad C_{\varepsilon 1}=1.44 \\
& \sigma_{k}=1.4, \quad \sigma_{\varepsilon}=1, \quad C_{\varepsilon 2}=1.92 \\
& f_{2}=1-0.3 \exp \left(-R_{t}^{2}\right), \quad R_{t}=\frac{k^{2}}{v_{l} \varepsilon}
\end{aligned}
$$

The wall boundary conditions for $\mathrm{k}$ and $\varepsilon$ are:

$$
\begin{aligned}
& k_{\text {wall }}=0 \\
& \varepsilon_{\text {wall }}=2 v_{l}\left(\frac{\partial \sqrt{k}}{\partial n}\right)^{2}
\end{aligned}
$$

The turbulent stress components for the linear model are formulated as:

$$
\overline{u_{i} u_{j}}=2 v_{t} S_{i j}-\frac{2}{3} \delta_{i j} k
$$

Where,

$$
S_{i j}=\frac{1}{2}\left[\frac{\partial u_{i}}{\partial x_{j}}+\frac{\partial u_{j}}{\partial x_{i}}\right]-\frac{1}{3} \delta_{i j} \frac{\partial u_{k}}{\partial x_{k}}
$$




$$
v_{t}=f_{\mu} C_{\mu}^{*} \frac{k^{2}}{\varepsilon}, f_{\mu}=\exp \left[\frac{-3.41}{\left(1+\frac{R_{t}}{50}\right)^{2}}\right]
$$

$C_{\mu}^{*}=0.09$ for the linear model. For the nonlinear models it is a function of the mean flow strain tensor and vorticity.

In the Shih-Zhu-Lumley (SZL) nonlinear model [17], the turbulent stresses are given by:

$$
-\overline{u_{i} u_{j}}=2 v_{t} S_{i j}-\frac{2}{3} \delta_{i j} k-2 \beta \frac{k^{3}}{\varepsilon^{2}}\left(W_{i k} S_{k j}-S_{i k} W_{k j}\right)
$$

whereas in the Girimaji nonlinear model [16], the turbulent stresses are given by:

$$
-\overline{u_{i} u_{j}}=2 \nu_{t} S_{i j}-\frac{2}{3} \delta_{i j} k-2 C_{\mu}^{*} \frac{k^{3}}{\varepsilon^{2}}\left[-G_{2}\left(W_{i k} \bar{S}_{k j}-\bar{S}_{i k} W_{k j}\right)+G_{3}\left(\bar{S}_{i k} \bar{S}_{k j}-\frac{1}{3} \bar{S}_{m n} \bar{S}_{m n} \delta_{i j}\right)\right]
$$

Where,

$$
\begin{gathered}
W_{i j}=\frac{1}{2}\left(\frac{\partial u_{i}}{\partial x_{j}}-\frac{\partial u_{j}}{\partial x_{i}}\right) \\
\bar{S}_{i j}=\frac{1}{2}\left[\frac{\partial u_{i}}{\partial x_{j}}+\frac{\partial u_{j}}{\partial x_{i}}\right]
\end{gathered}
$$

The additional variables used in two nonlinear models described above are defined in the Appendix.

\section{Flow Tripping Approach}

In the flow tripping approach, $\mathrm{k}$ and $\varepsilon$ solution as obtained from Eqs. (2) is overridden with the new profiles at all the grid cells in the plane normal to a specified trip region on the body surface. The procedure for computing these new profiles is illustrated next.

(2.1) Define a function $\Psi$ based on the mean flow vorticity $(\boldsymbol{W})$ and velocity $(\boldsymbol{U})$.

$$
\Psi=W U
$$

Where,

$$
\begin{aligned}
& W=\sqrt{W_{i j} W_{i j}}, \quad W_{i j}=\frac{1}{2}\left[\frac{\partial u_{i}}{\partial x_{j}}-\frac{\partial u_{j}}{\partial x_{i}}\right] \\
& U=\sqrt{u_{i}^{2}}
\end{aligned}
$$

(2.2) Set the turbulent kinetic energy profile based on the distribution of $\Psi$

$$
k=T^{2}\left(\frac{\Psi-\Psi_{\min }}{\Psi_{\max }-\Psi_{\min }}\right)
$$

Where, $T$ is turbulent intensity $\left(T=\alpha U_{\max }\right), \alpha=0.01-0.05$. 
(2.3) Calculate the $\varepsilon$ profile assuming that production is equal to dissipation.

$$
\begin{aligned}
& P=\varepsilon \\
& P \approx 2 v_{t} S_{i j} \frac{\partial u_{j}}{\partial x_{i}} \\
& \varepsilon=2 C_{\mu}^{*} \frac{k^{2}}{\varepsilon} S_{i j} \frac{\partial u_{j}}{\partial x_{i}} \\
& \varepsilon=\sqrt{2 C_{\mu}^{*} S_{i j} \frac{\partial u_{j}}{\partial x_{i}}} k
\end{aligned}
$$

\section{Modification to Turbulence Model Variables for Enforced Laminar Flow Region}

A simple approach to prescribe a laminar flow region on the computed flowfield is implemented in USM3D. This approach uses the same trip patch concept and the associated data structure as described in the preceding section. However, in the current method instead of prescribing a turbulent flow solution, a laminar flow condition is specified at the grid cells associated with the user-designated surface patches. This method has been implemented for all one- (SA) and two-equation (k- $\varepsilon$, SST) models of USM3D. The SA and SST solutions are obtained without changing the normal inflow values of the variables in these two respective models, due to the tendency of these models to provide a naturally transitioned turbulent flow in the immediate proximity of the stagnation point. The k- $\varepsilon$ model-based flow solutions are obtained using a high level of inflow turbulence $\left(\mathrm{k}^{*}=25 \times 10^{-8}, \mu_{t}^{*}=1.0\right)$.

\section{Results and Discussion}

\section{A. Forced Flow Transition}

This section describes the verification results for the presently implemented flow tripping capability in USM3D. The results are obtained for three test cases, namely, a flat plate, the RAE 2822 airfoil, and the DLR F6 wingfuselage configuration. The computed results are verified against the theory and the measured data. For all the cases, the flow transition from a laminar to a turbulent state is demonstrated using the contour plots of the maximum turbulence Mach number $\left(M_{t}=\sqrt{2 k} / a\right)$ that is projected on to the appropriate grid points on the body surface from inside the boundary layer.

\section{Flat Plate}

The first verification case considered is a flat plate with non-dimensional length of 4.25 and width of 0.17 . In the present method, a trip location on the body has to be specified using a surface patch. With this requirement in mind, the plate surface was represented using GridTool by several patches including three thin patches, each spanning the three arbitrarily chosen trip stations corresponding to the axial locations at $16.5 \%, 33 \%$, and $50 \%$ of the plate length. The width of the trip patches was restricted to be approximately $2 \%$ of the plate length.

Two unstructured grids with different stream wise grid resolution were generated for this case. Both the grids have identical body-normal spacing at the plate surface $\left(\right.$ cell $\left.\mathrm{y}^{+} \approx 0.25\right)$ and grid distribution across the boundary layer. The coarse grid consists of 15,382 triangular faces on the boundaries of the computational domain (604 faces on the plate surface) and 73,832 tetrahedral cells in the entire computational domain, whereas the fine grid consists of 41,610 triangular faces on the boundaries of the computational domain (1,948 faces on the plate surface) and 326,540 tetrahedral cells in the entire computational domain. Figure 3 presents a view of the coarse and fine grid triangulation of the plate surface. A close inspection of this figure reveals the topology of the underlying trip patches that have been manually created for this case.

All steady-state solutions for this case were obtained for a freestream Mach number of 0.5 and Reynolds number of 0.937 million per unit plate length. First, two sample flow solutions were obtained using the linear and a nonlinear k- $\varepsilon$ model to identify the most suitable model for this case. Based on the previous experience with nonlinear models in USM3D, the Girimaji nonlinear model was selected as the preferred nonlinear model and the SZL nonlinear model was not utilized in the present paper. For these sample solutions, the flow was assumed to be 
fully turbulent and accordingly high freestream turbulence values $\left(\mathrm{k}^{*}=100 \times 10^{-8}, \mu_{t}^{*}=1.0\right)$ were used. Additional reference solution based on the nonlinear model was also obtained by using low level $\left(\mathrm{k}^{*}=1 \times 10^{-8}, \mu_{t}^{*}=0.1\right)$ of freestream turbulence.

The accuracy of various computed solutions can be ascertained from Fig. 4 where the computed variations of local skin friction are compared with the corresponding theoretical values for the laminar and turbulent flows. It is evident from Fig. 4 that as compared to the nonlinear model and the White theory, the linear k- $\varepsilon$ model substantially over predicts the skin friction. It is also noted that while the nonlinear model based solution with low inflow turbulence accurately represents the theoretical laminar flow skin friction, the corresponding solution with high freestream turbulence again over predicts the theoretical skin friction for the turbulent flow. However, the nonlinear model as compared to the linear model is in better agreement with the turbulent flow theory. Carlson [22] has shown a strong correlation between the boundary layer grid density and the accuracy of the computed results. However, the objective of this study is the assessment of the flow tripping capability, and therefore no attempt was made to generate a grid with better resolution in the boundary layer.

Next, the effect of freestream turbulence on the computed solutions was assessed by assuming fully turbulent flow. The nonlinear $k-\varepsilon$ model was applied to obtain coarse grid solutions using four different levels of inflow turbulence that ranged from $\mathrm{k}^{*}=1 \times 10^{-8}, \mu_{t}^{*}=0.1$ to $\mathrm{k}^{*}=100 \times 10^{-8}, \mu_{t}^{*}=1.0$. Figure 5 shows the span wise and stream wise variation of the maximum turbulence Mach number inside the boundary layer that is projected on to the plate surface. It is interesting to observe that the lowest level freestream turbulence $\left(\mathrm{k}^{*}=1 \times 10^{-8}, \mu_{t}^{*}=0.1\right)$ produces a laminar flow on the entire length of the plate whereas the other three levels of freestream turbulence yield solutions with the varying extent of the laminar flow regions. For these three solutions, the stream wise location where the natural flow transition occurs is quite sensitive to the level of freestream turbulence, as seen from a substantial upstream shift of the transition point when freestream turbulence is increased from $\mathrm{k}^{*}=25 \times 10^{-8}, \mu_{t}^{*}=0.5$ to $\mathrm{k}^{*}=25 \times 10^{-8}, \mu_{t}^{*}=1.0$. The irregular span wise pattern of the transition line is also evident from the contour plots in Fig. 5.

The grid density also seems to play a dominant role in determining the transition location when a fully turbulent freestream flow is assumed. This is observed from Fig. 6 that shows the contour plots of the projected maximum turbulence Mach number from the coarse and fine grid solutions obtained using an identical level of inflow turbulence $\left(\mathrm{k}^{*}=25 \times 10^{-8}, \mu_{t}^{*}=0.5\right)$. Figure 6 shows that for the selected level of freestream turbulence, the flow transition occurs at about $60 \%$ of the plate length in the coarse grid solution. On the other hand, the flow remains laminar on the entire plate in the fine grid solution. Forgoing results show that the reliance on the freestream turbulence values to produce a fully turbulent flow can lead to arbitrary boundary layer solutions in which the flow transition may be quite random and it may depend on the grid resolution. Besides, a numerical solution obtained using an excessively high level of freestream turbulence may inhibit a physical process that can otherwise lead to the flow relaminarization.

The newly developed flow tripping capability is assessed next by computing three different flow solutions that are obtained by activating the flow tripping boundary condition at one of the three different locations shown on the surface grid in Fig. 7. Figure 7 also presents all the three flow solutions for this case. These solutions are obtained on the coarse grid using low freestream turbulence $\left(\mathrm{k}^{*}=1 \times 10^{-8}, \mu_{t}^{*}=0.1\right)$ that would produce a laminar flow solution in the absence of forced transition, as shown previously. It is evident from the maximum turbulence Mach number variations depicted in Fig. 7 that all the solutions demonstrate the onset of the turbulent flow state at the specified stream wise locations. Figure 8 provides a comparison of the local skin friction variations on the plate surface that are obtained from the three computed solutions and two theoretical results. The theoretical results correspond to the Blasius laminar flow solution and the White turbulent flow solution. It is seen from Fig. 8 that all the computed solutions obtained using low inflow turbulence closely agree with the laminar flow theory up to the respective trip stations. The computed solutions experience a steep rise in the skin friction values thereafter and follow the trend of the theoretical solution from White. The apparent discrepancy in the skin friction values among the three computed solutions is due to differences in the axial locations of various trip patches. Although not shown here, all the computed solutions nearly collapse to a single turbulent skin friction curve when the differences in the trip-station Reynolds number are reconciled for the abscissa of Fig. 8.

The computed solution corresponding to a trip location of $33 \%$ plate length is further investigated across the boundary layer at two stream wise stations; one upstream of the trip patch in the laminar flow region and another downstream of the trip patch in the turbulent flow region. The downstream location approximately corresponds to a momentum-thickness-based Reynolds number $\left(R_{\theta}\right)$ of 1420 . Figure 9(a) compares the variations of stream wise 
velocity $\left(\mathrm{u}^{+}\right)$across the boundary layer $\left(\mathrm{y}^{+}\right)$corresponding to the present computations and the Spalart [24] DNS results. The presently computed solution matches well with the DNS results in the post-trip turbulent boundary layer region. A variation of the turbulent kinetic energy across the boundary layer at two stream wise stations is presented in Fig. 9(b).

Additional fine grid solution was also obtained by tripping the flow at $33 \%$ of plate length as shown in Fig. 10. It is clear from this solution that the flow transitions to a turbulent state at a specified trip location for the fine grid as well. Figures 7 and 10 demonstrate that the flow transition line in the trip solutions does not depend on the grid density. It is also noted that all of the forced transition solutions exhibit minimal span wise deformation of the transition line.

\section{RAE 2822 Airfoil}

This case will facilitate the verification of the present method on a two-dimensional configuration that presents a flow with surface pressure gradient and a shock. The airfoil has been extensively tested and the measured data have been reported in Ref. [25]. The computed solutions for this case were obtained considering Case 10 of the data set and accordingly a freestream flow of Mach number 0.75 and Reynolds number of 6.2 million at 2.72-deg. angle-ofattack was considered and the forced flow transition solutions were obtained by simulating the upper and the lower airfoil surface trips at $3 \%$ of the chord.

A quasi three-dimensional simulation of this two-dimensional problem was performed in this study by considering a two-end-wall-mounted rectangular wing that is made up of RAE 2822 airfoil cross-sections. The viscous $\left(\right.$ cell $\left.\mathrm{y}^{+} \approx 0.25\right)$ unstructured grid used for this case consisted of 4,202 wing-surface-triangles and a total of 815,529 tetrahedral cells. Figure 11 presents a view of the wing surface grid. The triangles shown in the red color in Fig. 11 were extracted from the surface grid using PREDISC, to define the trip patches where the trip boundary condition was activated for the forced flow transition computations.

Initially, two flow solutions were computed without activating the trip boundary condition. These solutions were obtained by using a low $\left(\mathrm{k}^{*}=1 \times 10^{-8}, \mu_{t}^{*}=0.1\right)$ and a high $\left(\mathrm{k}^{*}=100 \times 10^{-8}, \mu_{t}^{*}=1.0\right)$ level of freestream turbulence. The low turbulence level solution failed to converge whereas the high turbulence level solution asymptotically converged to a steady-state. Figure 12 displays the characteristics of these solutions by using the longitudinal and lateral variation of the maximum turbulence Mach number in the boundary layer. It can be readily seen from Fig. 12 that the freestream turbulence level has a marked effect on the flow solutions. The wing lower surface flow is laminar in the solution obtained with a low level of freestream turbulence whereas the flow transitions from a laminar to a turbulent state in the vicinity of the stagnation point in the solution obtained with a high level of freestream turbulence. On the wing upper surface, a laminar flow exists up to about $60 \%$ of the chord and it becomes turbulent thereafter in the solution obtained with a low level of inflow turbulence. In the solution corresponding to a high level of inflow turbulence, the upper surface flow transitions to a turbulent state at about $8 \%$ of the chord. The latter solution shows that the flow transition is quite random, as indicated by an irregular topology of the transition line in the span wise direction. A further investigation of these solutions was conducted by examining the computed surface pressures at a mid-span location on the wing. A comparison of the computed pressures with the measured data is presented in Fig. 13. The solution computed using low inflow turbulence is quite oscillatory on the airfoil lower surface and suggests a laminar unsteady flow state, also exemplified by the highly oscillatory solution convergence history. The high-freestream-turbulence solution converges to a steady state and shows a close agreement with the measure data.

Next, the forced transition solution was obtained by activating the trip boundary condition on the wing upper and lower surface trip patches. This solution was obtained by using the same low inflow turbulence level $\left(\mathrm{k}^{*}=1 \times 10^{-8}\right.$, $\left.\mu_{t}^{*}=0.1\right)$ as the one used for computing one of the two previously described flow solutions. However, unlike the latter, this solution asymptotically converged to a steady-state. The boundary layer flow characteristics are examined in Fig. 14, again by capturing the longitudinal and lateral variation of the maximum turbulence Mach number. It is observed from Fig. 14 that the flow becomes turbulent precisely on the prescribed upper and lower surface trip patches. Figure 15 presents a comparison of mid-span wing surface pressures from the present solution with the corresponding pressures from the previous high-freestream-turbulence solution obtained without forced transition and the measured data. The present solution compares very well with the previous solution and the measured data.

\section{DLR F6 Wing-Fuselage Configuration}

This test case was selected to verify the method on a more representative three-dimensional configuration that has been extensively investigated in various studies conducted as part of AIAA second Drag Prediction Workshop (DPW II). The computed solutions for this case were obtained considering a freestream flow of Mach number 0.75 
and Reynolds number of 3 million at 0-deg. angle-of-attack. The forced flow transition solution was obtained by simulating the upper and the lower wing surface trips at $10 \%$ and $25 \%$ of the chord respectively, and fuselage trip at $3 \%$ of the body-length.

The unstructured grid used for this case consisted of 48,753 body-surface-triangles and a total of 5,528,476 tetrahedral cells. The grid has 45 cells in the entire boundary layer and the first layer of grid cells around the configuration surface is located at a distance of $y^{+} \approx 0.75$. Figure 1 presents a view of the surface grid for this configuration. The trip patches shown in Fig. 1 were defined using PREDISC that grouped various surface triangles in to separate new patches at the specified trip locations.

As in the previous test case, three different solutions were computed for this case. Two of these solutions were obtained without activating the trip boundary condition. These solutions were obtained by using a low $\left(\mathrm{k}^{*}=1 \times 10^{-8}\right.$,

$\left.\mu_{t}^{*}=0.1\right)$ and a high $\left(\mathrm{k}^{*}=100 \times 10^{-8}, \mu_{t}^{*}=1.0\right)$ level of freestream turbulence. The third solution was generated by activating the trip boundary condition and using a low $\left(\mathrm{k}^{*}=1 \times 10^{-8}, \mu_{t}^{*}=0.1\right)$ level of inflow turbulence.

Both, the high and low inflow turbulence solutions without flow tripping showed fluctuations in the overall solution error reduction. However, the aerodynamic forces and moments were well converged in the solution with high inflow turbulence. The solution with active trips also converged to a steady-state in spite of using low inflow turbulence level. The convergence behavior of various solutions can be followed in Fig. 16 that provides the history of solution residual error and total drag coefficient. The lift and drag coefficients from various solutions are summarized in Table 1. The boundary layer flow characteristics of the two types of solutions, namely, the ones without and with forced flow transition, are presented in Fig. 17 and Fig. 18, respectively. The solution with the activated trip boundary condition exhibits a well-defined flow transition pattern.

Table 1. Summary of the DLR F6 wing-fuselage force coefficients computed using a nonlinear k- $\varepsilon$ model with and without forced transition.

\begin{tabular}{|l|l|l|l|}
\hline & $\mathbf{C}_{\mathbf{L}}$ & $\mathbf{C}_{\mathbf{D}}$ & $\mathbf{C}_{\mathbf{D v}}$ \\
\hline $\begin{array}{l}\text { without tripping, } \\
\text { low inflow turbulence }\end{array}$ & 0.528 & 0.0273 & 0.0099 \\
\hline $\begin{array}{l}\text { without tripping, } \\
\text { high inflow turbulence }\end{array}$ & 0.512 & 0.0329 & 0.0155 \\
\hline $\begin{array}{l}\text { with tripping, } \\
\text { low inflow turbulence }\end{array}$ & 0.505 & 0.0331 & 0.0158 \\
\hline
\end{tabular}

\section{B. Enforced Laminar Flow Region}

In this section some preliminary solutions will be presented that are obtained by leveraging the presently developed data structure to enforce a laminar flow region on the otherwise-turbulent-flow solution. The DLR F6 configuration was used for this purpose. Figure 19 shows the extent of the laminar flow region specified on various surfaces using the trip patch concept. Two flow solutions using the Spalart-Allmaras one-equation model and Menter SST model were computed for a freestream of Mach number 0.75 and Reynolds number of 3 million at 0 deg. angle-of-attack. These solutions are presented in Fig. 20 using the variation of surface skin friction. Table 2 summarizes the surface forces computed using two turbulence models.

Table 2. Summary of the DLR F6 wing-fuselage force coefficients computed using two turbulence models with a prescribed laminar flow region.

\begin{tabular}{|l|l|l|l|}
\hline & $\mathbf{C}_{\mathbf{L}}$ & $\mathbf{C}_{\mathbf{D}}$ & $\mathbf{C}_{\mathbf{D v}}$ \\
\hline S-A one-equation model & 0.532 & 0.0292 & 0.0120 \\
\hline Menter's SST model & 0.483 & 0.0293 & 0.0127 \\
\hline
\end{tabular}

\section{IV. $\square$ Conclusion}

In the present paper, USM3D implementation of a forced flow transition approach was described and successfully verified. The approach is based on the assumption that in the transition region the turbulence production equals the dissipation that has been extensively used in the PAB3D structured grid code. The method can be primarily utilized to more closely match the experiments conducted with transition strips. It can also be used to mitigate the well-known deficiency of some low-Reynolds number k- $\varepsilon$ formulation-based flow solutions. Such solutions contain varying sizes of the laminar flow regions and depend on the prescribed inflow turbulence, grid 
resolution, and the inherent dissipation of a numerical scheme. The verification studies of the present implementation were conducted on three test cases, namely, a flat plate, the RAE 2822 airfoil, and the DLR F6 wing-fuselage configuration.

The flat plate case demonstrated the effects of grid resolution and inflow turbulence level on the solutions obtained without enforcing the flow transition. This deficiency was successfully eliminated using the present flow tripping method. Furthermore, the RAE 2822 airfoil case showed that the k- $\varepsilon$ turbulence model could produce an unsteady solution when a low freestream turbulence level is used. By enforcing the flow transition at a prescribed location, a steady-state flow solution was recovered for this case, in spite of using a lower level of inflow turbulence.

The present approach uses a graphical user-interface tool PREDISC to define a trip region on the body surface in an existing grid. This element of the method can greatly simplify the setup of forced transition cases for complex configurations. The present approach will be extended to other turbulence models in the future.

Another adjunct approach to facilitate the specification of a laminar flow region was presented that leveraged the data structure developed for the forced transition mechanism. Preliminary computations were presented using several one- and two-equation models.

\section{Appendix}

Nonlinear Algebraic Stress Model Equation variables and constants have been defined below.

For the SZL model shown in Eq. (5),

$$
\begin{gathered}
\beta=\frac{\sqrt{1-9 C_{\mu}^{2}\left(\frac{S k}{\varepsilon}\right)^{2}}}{\left(1+6 \frac{S k}{\varepsilon} \frac{W k}{\varepsilon}\right)} \\
C_{\mu}^{*}=\frac{1}{\left(6.5+A_{s}^{*} \frac{U^{*} k}{\varepsilon}\right)}
\end{gathered}
$$

Where,

$$
\begin{aligned}
& A_{s}^{*}=\sqrt{6} \cos (\phi) \\
& \phi=\frac{1}{3} \cos ^{-1}\left(\sqrt{6} S^{*}\right) \\
& S^{*}=S_{i j} S_{j k} S_{k i} /(S)^{3} \\
& U^{*}=\sqrt{S_{i j} S_{i j}+W_{i j} W_{i j}} \\
& W=\sqrt{W_{i j} W_{i j}}
\end{aligned}
$$

For the Girimaji model shown in Eq. (6),

$$
\begin{aligned}
G_{2} & =\frac{-L_{4} G_{1}}{L_{1}^{0}-\eta_{1} L_{1}^{1} G_{1}} \\
G_{3} & =\frac{-L_{3} G_{1}}{L_{1}^{0}-\eta_{1} L_{1}^{1} G_{1}} \\
C_{\mu}^{*} & =-G_{1}
\end{aligned}
$$

Where, 


$$
\begin{aligned}
& G_{1}= \begin{cases}L_{1}^{0} L_{2} /\left[\left(L_{1}^{0}\right)^{2}+2 \eta_{2}\left(L_{4}\right)^{2}\right] & \text { for } \eta_{1}=0 \\
-\frac{p}{3}+\left(-\frac{b}{2}+\sqrt{D}\right)^{1 / 3}+\left(-\frac{b}{2}-\sqrt{D}\right)^{1 / 3} & \text { for } D>0 \\
-\frac{p}{3}+2 \sqrt{\frac{-a}{3}} \cos \left(\frac{\theta}{3}\right) & \text { for } D<0, b<0 \\
-\frac{p}{3}+2 \sqrt{\frac{-a}{3}} \cos \left(\frac{\theta}{3}+\frac{2 \pi}{3}\right) & \text { for } D<0, b>0\end{cases} \\
& L_{1}^{0}=\frac{C_{1}^{0}}{2}-1 \quad L_{1}^{1}=C_{1}^{1}+2 \\
& L_{2}=\frac{C_{2}}{2}-\frac{2}{3} \quad L_{3}=\frac{C_{3}}{2}-1 \quad L_{4}=\frac{C_{4}}{2}-1 \\
& \eta_{1}=\left(\frac{k}{\varepsilon}\right)^{2} \bar{S}_{m n} \bar{S}_{m n} \\
& \eta_{2}=\left(\frac{k}{\varepsilon}\right)^{2} W_{m n} W_{m n} \\
& D=\frac{b^{2}}{4}+\frac{a^{3}}{27} \\
& \cos (\theta)=\frac{-b / 2}{\sqrt{-a^{3} / 27}} \\
& b=\frac{1}{27}\left(2 p^{3}-9 p q+27 r\right), \quad a=\left(q-\frac{p^{2}}{3}\right) \\
& p=-\frac{2 L_{1}^{0}}{\eta_{1} L_{1}^{1}}, \quad q=\frac{1}{\left(\eta_{1} L_{1}^{1}\right)^{2}}\left[\left(L_{1}^{0}\right)^{2}+\eta_{1} L_{1}^{1} L_{2}-\frac{2}{3} \eta_{1}\left(L_{3}\right)^{2}+2 \eta_{2}\left(L_{4}\right)^{2}\right], \quad r=-\frac{L_{1}^{0} L_{2}}{\left(\eta_{1} L_{1}^{1}\right)^{2}} \\
& C_{1}^{0}=3.4, C_{1}^{1}=1.8, C_{2}=0.36, C_{3}=1.25, C_{4}=0.4
\end{aligned}
$$

\section{Acknowledgments}

The work of the first author was performed under a NASA contract NAS1-00135 while employed by Swales Aerospace, Hampton, VA. The technical monitor was Dr. Neal T. Frink of the Configuration Aerodynamics Branch (CAB), NASA Langley Research Center (LaRC). The funding support provided by the High Lift Slotted Wing project under the Efficient Aerodynamic Shape Integration (EASI) program is gratefully acknowledged. The technical monitor for the present work was Dr. Steve Krist of CAB, NASA LaRC. The authors wish to thank Dr. Krist for many fruitful discussions and valuable feedback related to this work.

\section{References}

[1] Rumsey, C. L., Pettersson Reif, B. A., and Gatski, T. B., "Arbitrary Steady-State Solutions with the K-Epsilon Model", Submitted for AIAA Journal 2005.

[2] Frink, N. T., Pirzadeh, S. Z., Parikh, P. C., and Pandya, M. J., "The NASA Tetrahedral Unstructured Software System (TetrUSS)," The Aeronautical Journal, Vol.104, No. 1040, October 2000, pp. 491-499.

[3] Samareh, J., "GridTool: A Surface Modeling and Grid Generation Tool," Proceedings of the Workshop on Surface Modeling, Grid Generation, and Related Issues in CFD Solutions," NASA CP-3291, 9-11 May, 1995.

[4] Pirzadeh, S., "Structured Background Grids for Generation of Unstructured Grids by Advancing Front Method," AIAA Journal, Vol. 31, No. 2, February 1993, pp. 257-265. 
[5] Pirzadeh, S., "Unstructured Viscous Grid Generation by Advancing-Layers Method," AIAA Journal, Vol. 32, No. 8, August 1994, pp. 1735-1737.

[6] Frink, N. T., "Upwind Scheme for Solving the Euler Equations on Unstructured Tetrahedral Meshes," AIAA Journal, Vol., No. 1, January 1992, pp. 70-77.

[7] Frink, N. T., "Tetrahedral Unstructured Navier-Stokes Method for Turbulent Flows," AIAA Journal, Vol. 36, No. 11, November 1998, pp. 1975-1982.

[8] Roe, P., "Characteristic Based Schemes for the Euler Equations," Annual Review of Fluid Mechanics, Vol. 18, 1986, pp. 337-365.

[9] Frink, N. T., "Recent Progress Toward a Three-Dimensional Unstructured Navier-Stokes Flow Solver," AIAA 94-0061, January 1994.

[10] Anderson, W., and Bonhaus D., "An Implicit Upwind Algorithm for Computing Turbulent Flows on Unstructured Grids," Computers Fluids, Vol. 23, No. 1, 1994, pp. 1-21.

[11] Spalart P., and Allmaras S. A., "One-equation Turbulence Model for Aerodynamic Flows," AIAA Paper 920439, January 1992.

[12] Jones,W. P., and Launder, B. E., "The Prediction of Laminarization With a Two-Equation Model of Turbulence," Int. J. Heat \& Mass Transf., vol. 15, no. 2, Feb. 1972, pp. 301-314.

[13] Sarkar, S., Erlebacher, G., Hussaini, M. Y., and Kreiss, H. O., "The Analysis and Modeling of Dilatational Terms in Compressible Turbulence," J. Fluid Mech., vol. 227, June 1991, pp. 473-495.

[14] Menter, F. R., "Improved Two-Equation k-omega Turbulence Models for Aerodynamic Flows", NASA TM103975, October 1992.

[15] Abdol-Hamid, K. S. Frink, N. T., Deere, K. A., and Pandya, M. J., "Propulsion Simulations Using Advanced Turbulence Models with the Unstructured-Grid CFD Tool, TetrUSS," AIAA Paper 2004-0714, January 2004.

[16] Girimaji, S. S., "Fully-Explicit and Self-Consistent Algebraic Reynolds Stress Model," ICAS Report 95-82, 1995.

[17] Shih, T-H., Zhu, J., and Lumley, J. L., “A New Reynolds Stress Algebraic Model,” NASA TM-166614, ICOMP 94-8, 1994.

[18] Frink, N. T., Bonhaus, D. L., Vatsa, V. N., Bauer, S. X. S., and Tinetti, A .F., "A Boundary Condition for Simulation of Flow Over Porous Surfaces," Journal of Aircraft, vol. 40, no. 4, July-August 2003, pp. 692-698.

[19] Pandya, M. J., Frink, N. T., Abdol-Hamid, K. S., and Chung, J. J., "Recent Enhancements to USM3D Unstructured Flow Solver for Unsteady Flows," AIAA Paper 2004-5201, August 16-19 2004.

[20] Pandya, M. J., Frink, N. T., and Noack, R. W., "Overset-Grid Moving Body Capability in the USM3D Unstructured Flow Solver," AIAA Paper 2005-5118, June 6-9 2005.

[21] Campbell, R. L., Carter, M. B., Pendergraft, O. C., Jr., Friedman, D. M., and Serrano, L., "Design and Testing of a Blended Wing Body with Boundary Layer Ingestion Nacelles at High Reynolds Numbers (Invited)," AIAA-2005-0459, January 2005.

[22] Carlson, J., "Applications of Algebraic Reynolds Stress Turbulence Models Part 1: Incompressible Flat Plate," Journal of Propulsion and Power, vol. 13, no. 5, September-October 1997, pp. 610-619.

[23] PAB3D Code Manual: http://www.asm-usa.com/software/PAB3D, Originally developed by the Propulsion Aerodynamics Branch, now under a cooperative program between the Configuration Aerodynamics Branch, NASA Langley Research Center and Analytical Services \& Materials, Inc. Hampton, VA.

[24] Spalart, P. R., "Direct Numerical Simulations of Turbulent Boundary Layers up to $\operatorname{Re}_{\mathrm{e}}=1420$," Journal of Fluid Mechanics, Vol. 187, 1988, pp. 61-98.

[25]Cook, P. H., McDonald, M. A., and Firmin, M. C. P., "Airfoil RAE 2822 - Pressure Distributions, and Boundary Layer and Wake Measurements," AGARD-AR-138, 1979. 


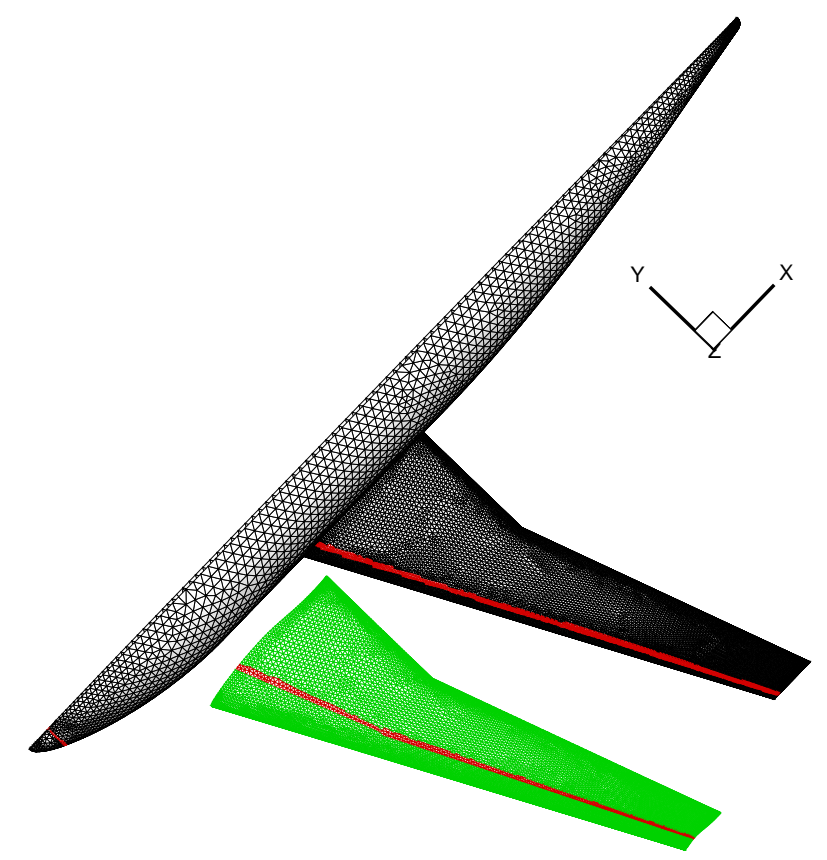

Figure 1. Arrangement of trip patches extracted using PREDISC from an existing grid for the DLR F6 wing-fuselage configuration. Wing lower surface (green color) lofted out for clarity.

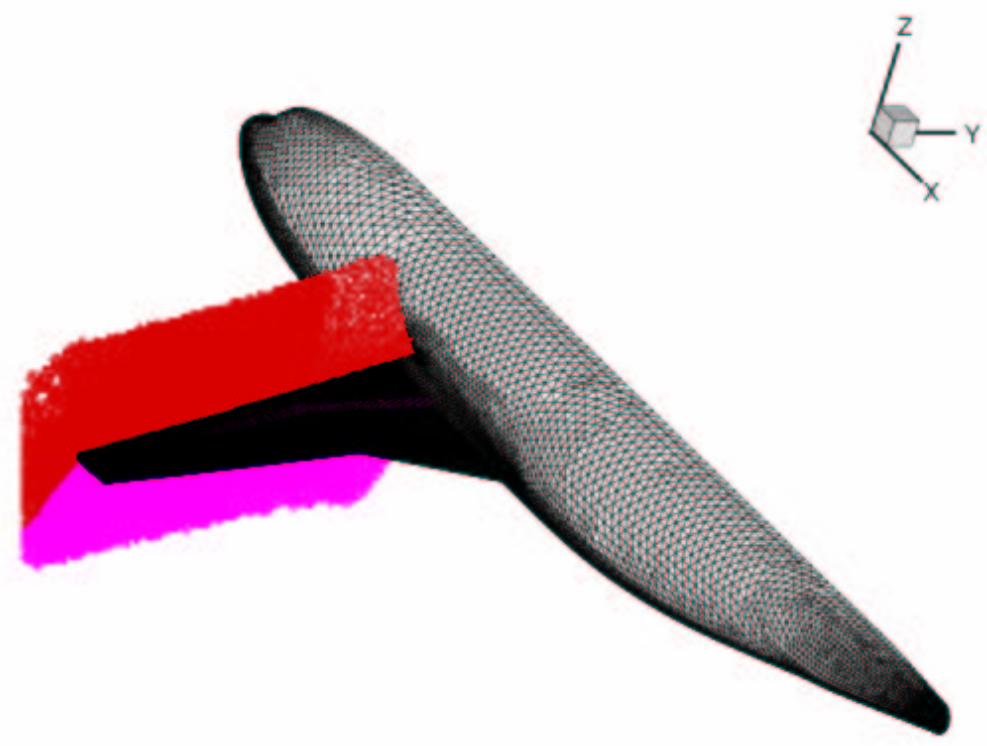

Figure 2. Schematic view of the tetrahedral grid cells identified to prescribe a new turbulence model solution in the flow tripping mechanism. Tetrahedral cells associated with the wing upper surface trip patch (red color) and lower surface trip patch (purple color). 


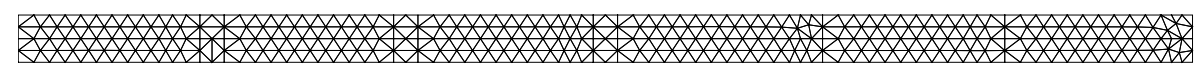

(a)

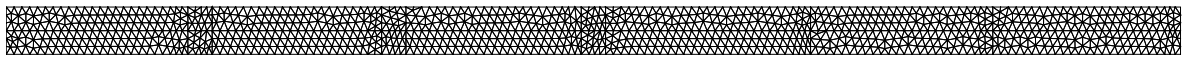

(b)

Figure 3. Flat plate surface triangulation. (a) coarse grid, 604 faces on plate surface (b) fine grid, 1,948 faces on plate surface.

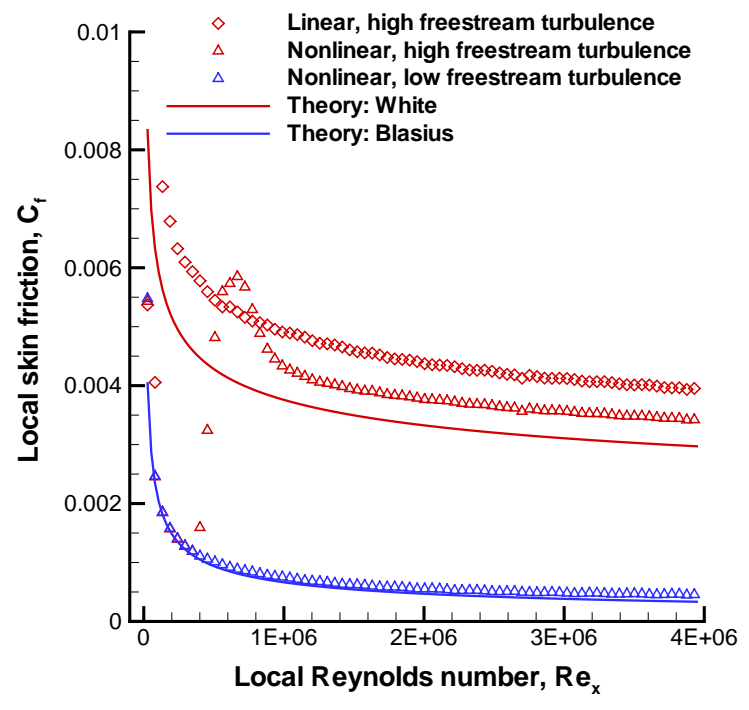

Figure 4. Comparison of computed and theoretical local skin friction distributions on a flat plate. Computed results correspond to linear and a nonlinear k- $\varepsilon$ turbulence models obtained without activating flow tripping and using two different levels of freestream turbulence. 


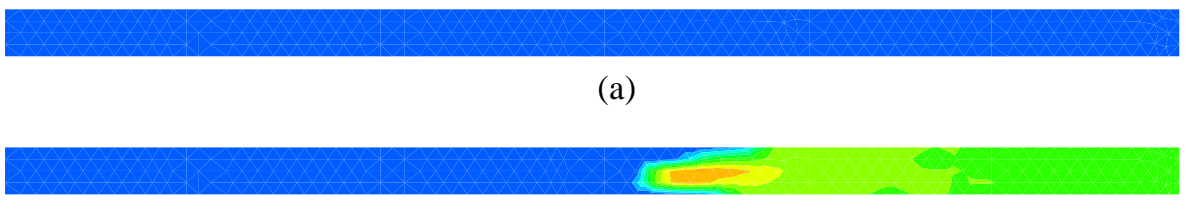

(b)

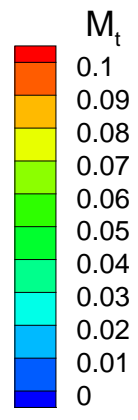

(c)

(d)

Figure 5. Contour plots of the computed maximum turbulence Mach number projected on the surface from the boundary layer. Computed results correspond to coarse grid solutions obtained without activating flow tripping and using different levels of freestream turbulence (a) $\mathbf{k}^{*}=1 \times 10^{-8}, \mu_{t}^{*}=0.1$ (b) $\mathbf{k}^{*}=25 \times 10^{-8}, \mu_{t}^{*}=0.5$ (c) $\mathbf{k}^{*}=25 \times 10^{-8}, \mu_{t}^{*}=1.0(\mathbf{d}) \mathbf{k}^{*}=100 \times 10^{-8}, \mu_{t}^{*}=1.0$.

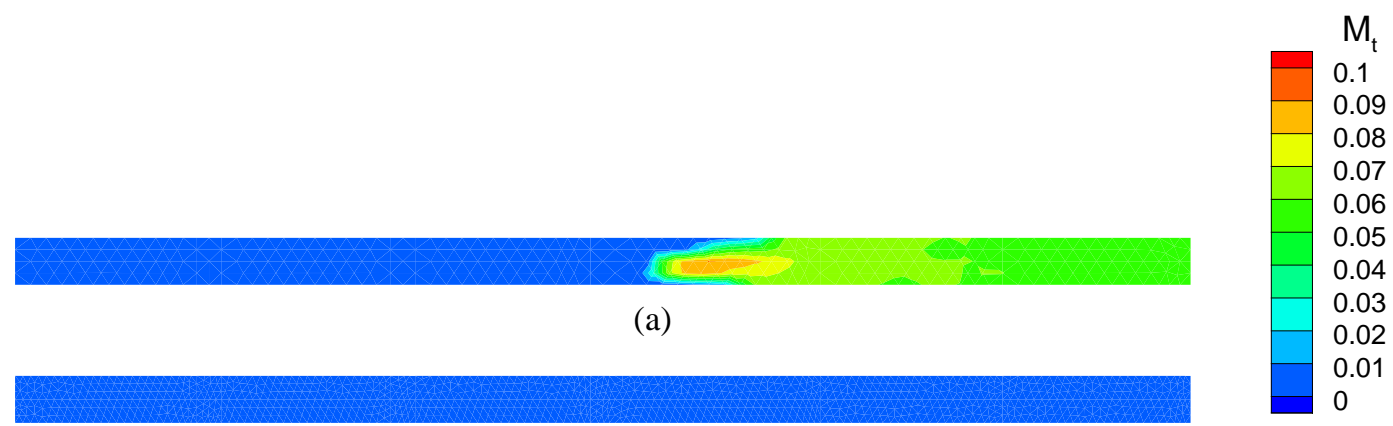

(b)

Figure 6. Contour plots of the computed maximum turbulence Mach number projected on the surface from the boundary layer. Results obtained without activating flow tripping and using the identical value of freestream turbulence $\left(\mathrm{k}^{*}=25 \times 10^{-8}, \mu_{t}^{*}=0.5\right)$. (a) Coarse grid (b) Fine grid.
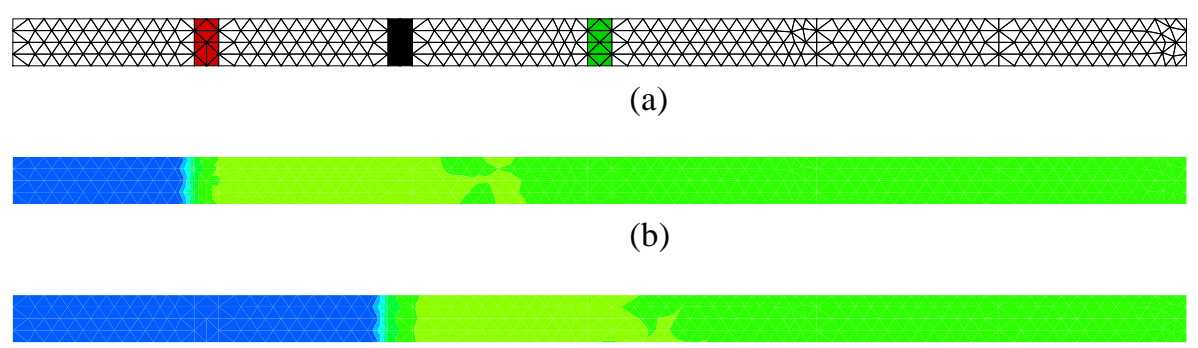

(b)

(c)

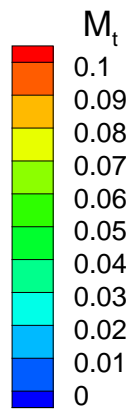

(d)

Figure 7. Assessment of the flow tripping capability on a flat plate. (a) View of the plate surface trip patches in the coarse grid (b-d) Coarse grid solutions using low freestream turbulence value $\left(\mathrm{k}^{*}=1 \times 10^{-8}\right.$, $\mu_{t}^{*}=0.1$ ) and tripping active at various axial locations (b) $16.5 \%$ (c) $33 \%$ and (d) $50 \%$ of the plate length. Computational results show maximum turbulence Mach number projected on the surface from the boundary layer. 


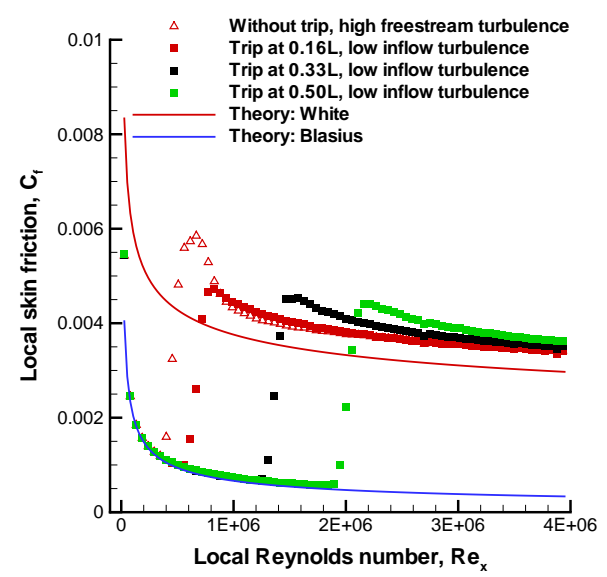

Figure 8. Comparison of the computed and the theoretical local skin friction distributions on a flat plate. Computed results correspond to various coarse grid solutions obtained by activating flow tripping at different axial locations on the flat plate.

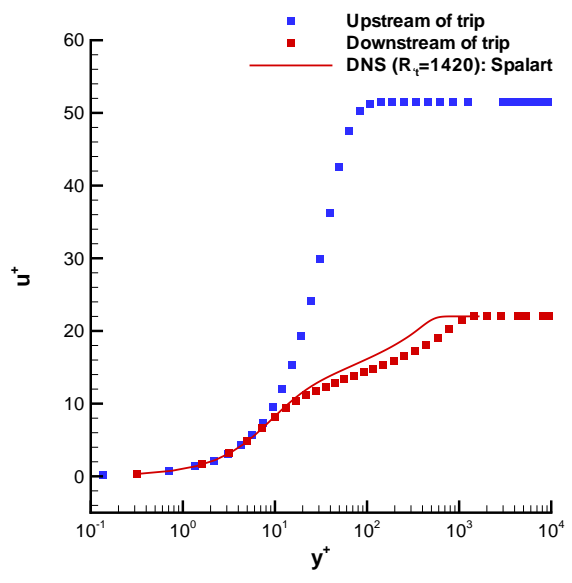

(a)

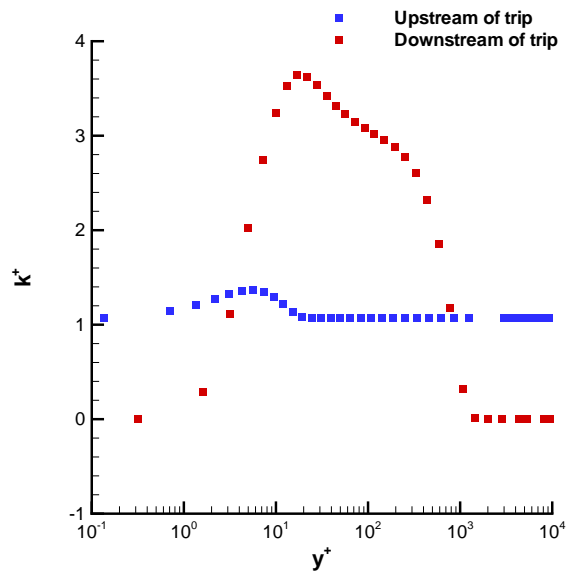

(b)

Figure 9. Investigation of the computed boundary layer profile at two stream wise stations on the flat plate obtained from a coarse grid solution corresponding to the flow tripping at $50 \%$ plate length. Variation across the boundary layer of (a) stream wise velocity (b) turbulent kinetic energy.

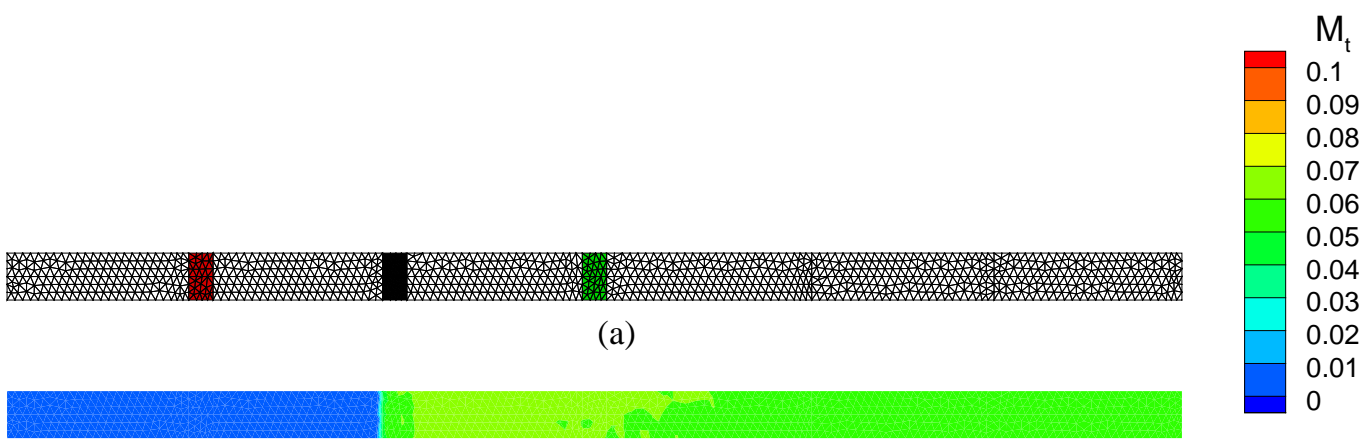

(b)

Figure 10. Assessment of grid density effect on the forced trip solutions. (a) View of the plate surface trip patches in the fine grid (b) Fine grid solution using low freestream turbulence value $\left(\mathrm{k}^{*}=1 \times 10^{-8}, \mu_{t}^{*}=0.1\right)$ and tripping active at $33 \%$ of the plate length. Contour plots show the computed maximum turbulence Mach number projected on the surface from the boundary layer. 


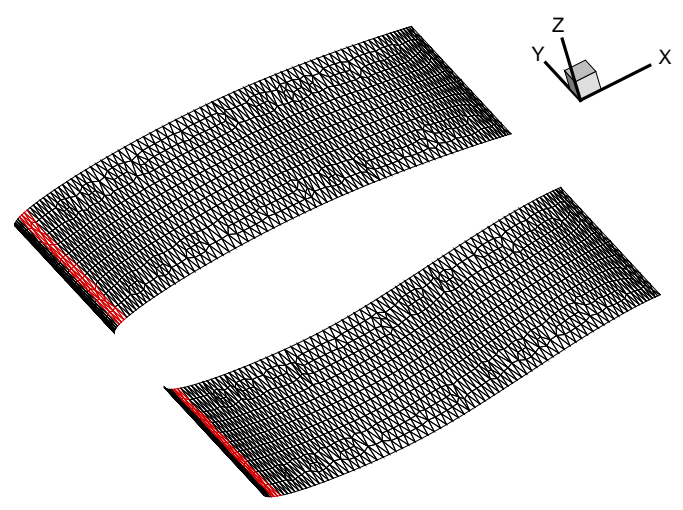

Figure 11. View of the surface grid and a trip patch layout for the RAE 2822 rectangular wing.

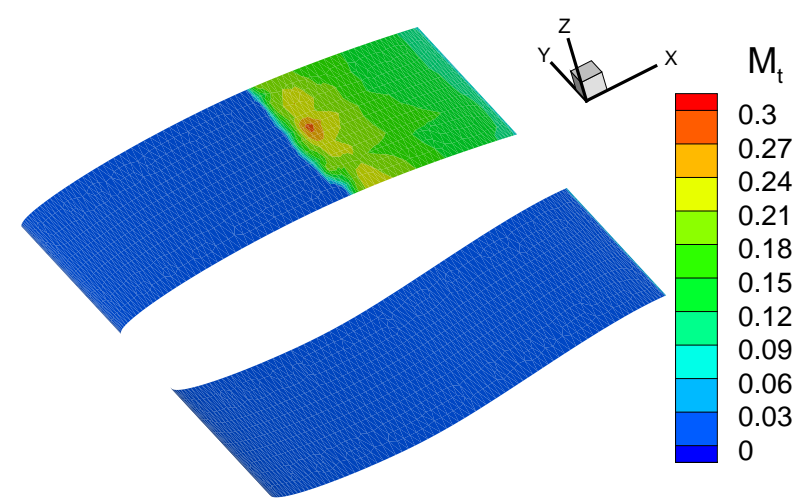

(a)

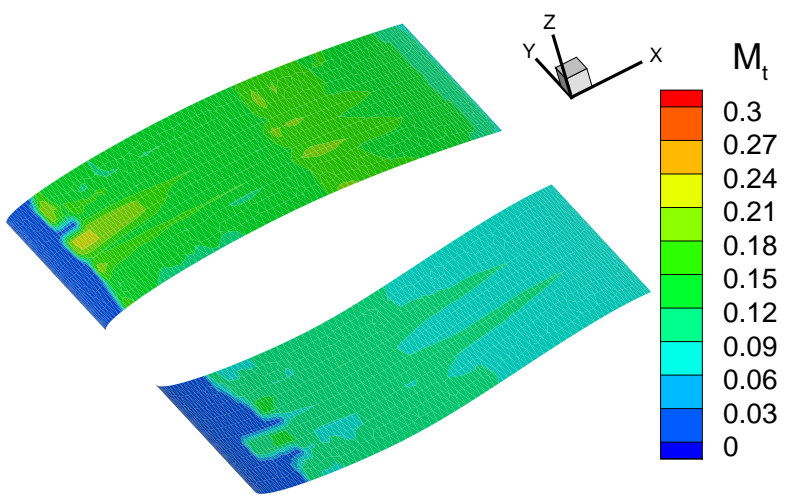

(b)

Figure 12. RAE 2822 flow solutions without flow tripping obtained for $M_{\infty}=0.75, \propto=2.72^{\circ}, R_{c}=6.2 \times 10^{6}$ considering two different levels of freestream turbulence. (a) $\mathbf{k}^{*}=1 \times 10^{-8}, \mu_{t}^{*}=0.1$ (b) $\mathbf{k}^{*}=100 \times 10^{-8}, \mu_{t}^{*}=1.0$. 


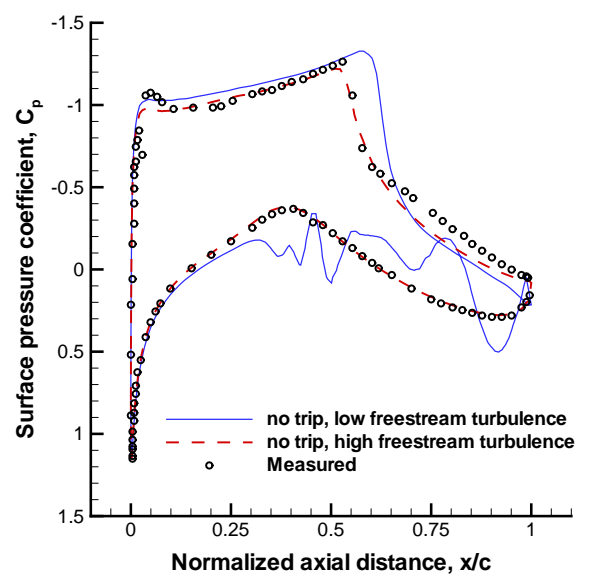

Figure 13. Comparison of the computed and measured surface pressure coefficients on the RAE 2822 airfoil section for $M_{\infty}=0.75, \propto=2.72^{\circ}, R_{c}=6.2 \times 10^{6}$. Computed solutions obtained without flow tripping and considering two different levels of freestream turbulence.

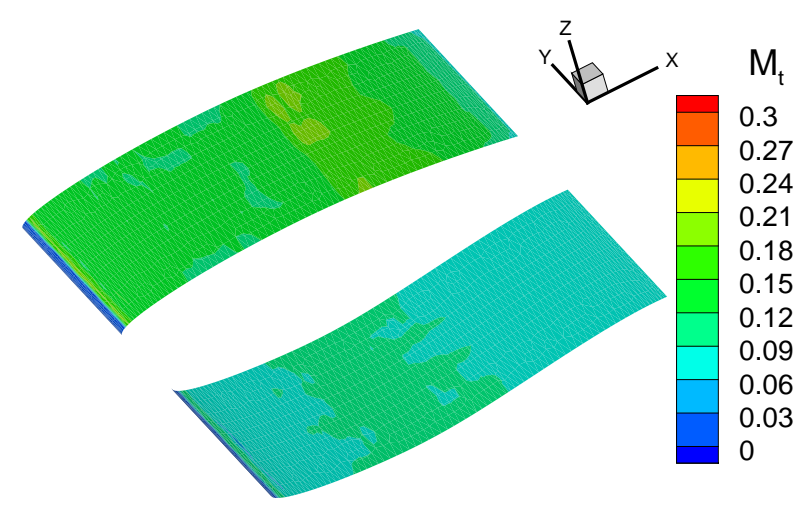

Figure 14. RAE 2822 flow solution obtained by using a low inflow turbulence $\left(\mathrm{k}^{*}=1 \times 10^{-8}, \mu_{t}^{*}=0.1\right)$ and tripping the flow at 3\% airfoil chord on the upper and lower wing surfaces. The solution obtained for $M_{\infty}=0.75, \propto=2.72^{\circ}, \operatorname{Re}_{c}=6.2 \times 10^{6}$.

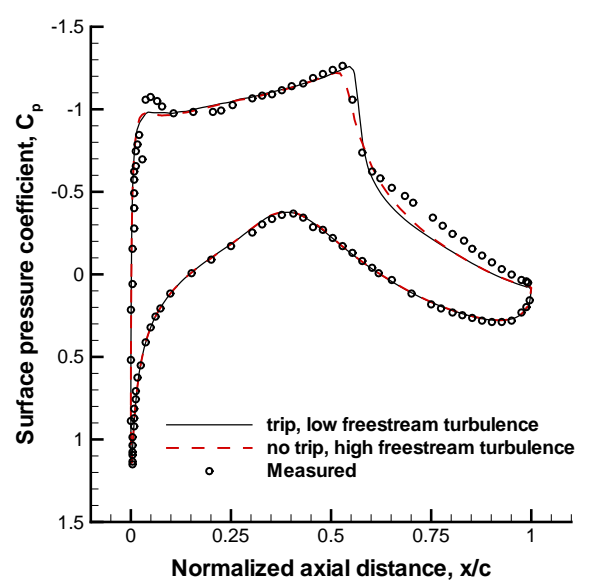

Figure 15. Comparison of the computed and measured surface pressure coefficients on the RAE 2822 airfoil section for $M_{\infty}=0.75, \propto=2.72^{\circ}, R_{c}=6.2 \times 10^{6}$. Computed solutions obtained without flow tripping and considering two different levels of freestream turbulence. 


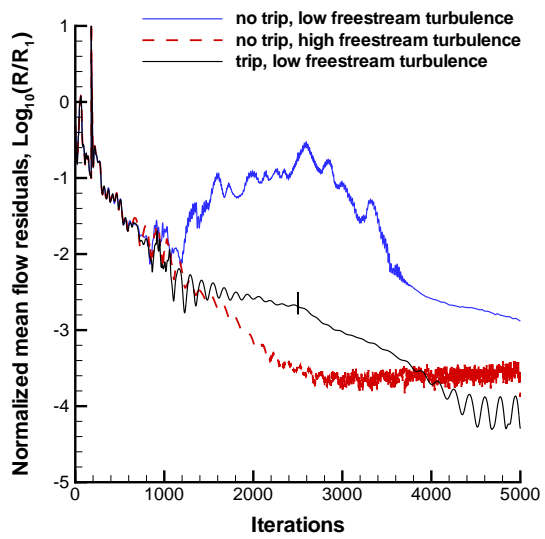

(a)

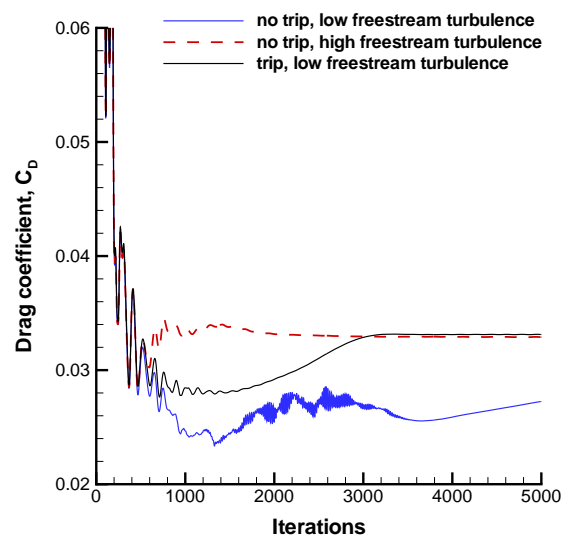

(b)

Figure 16. Solution convergence history plots for the DLR F6 wing-fuselage configuration. Computed solutions for $M_{\infty}=0.75, \propto=0^{\circ}, R_{c}=3 \times 10^{6}$ obtained with and without flow tripping and using two different levels of freestream turbulence $\left(\mathbf{k}^{*}=1 \times 10^{-8}, \mu_{t}^{*}=0.1, \mathbf{k}^{*}=100 \times 10^{-8}, \mu_{t}^{*}=1.0\right)$. (a) residual error (b) drag coefficient.

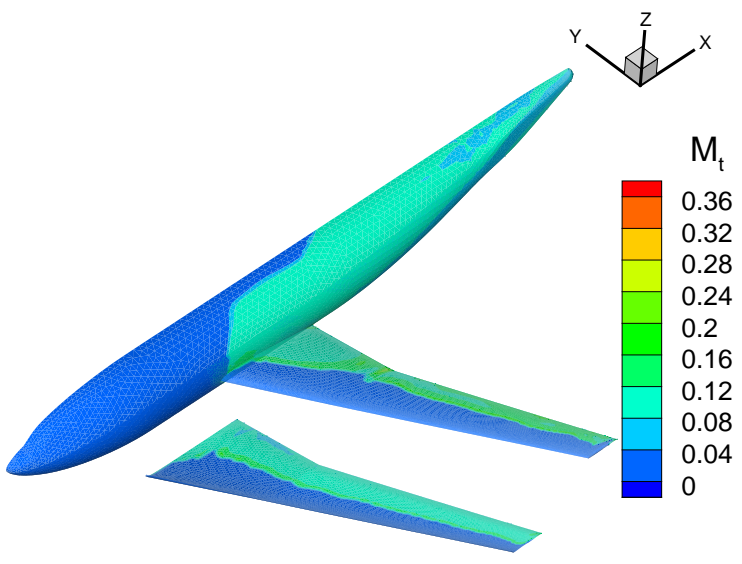

(a)

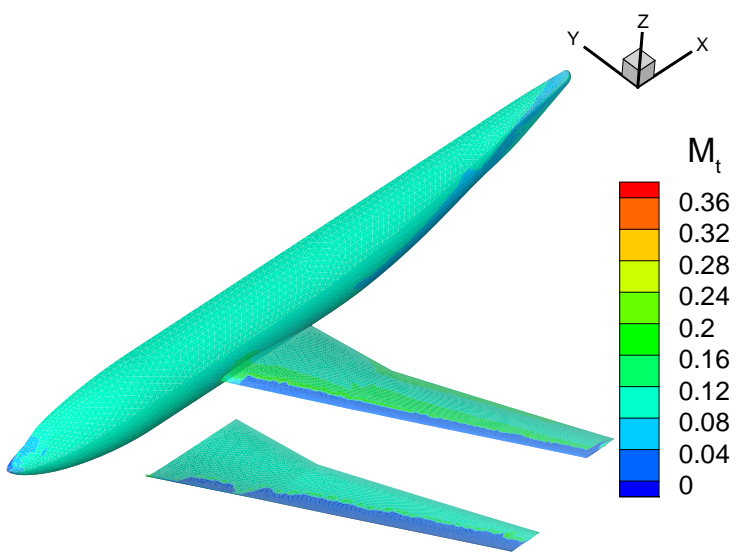

(b)

Figure 17. DLR F6 wing-fuselage solution of the computed maximum turbulence Mach number projected on the surface from the boundary layer. Computed solutions for $M_{\infty}=0.75, \propto=0^{\circ}, R_{c}=3 \times 10^{6}$ obtained without activating flow tripping and using two levels of freestream turbulence (a) low level $\left(\mathrm{k}^{*}=1 \times 10^{-8}\right.$, $\left.\mu_{t}^{*}=0.1\right)(\mathbf{b})$ high level $\left(\mathbf{k}^{*}=100 \times 10^{-8}, \mu_{t}^{*}=1.0\right)$. 


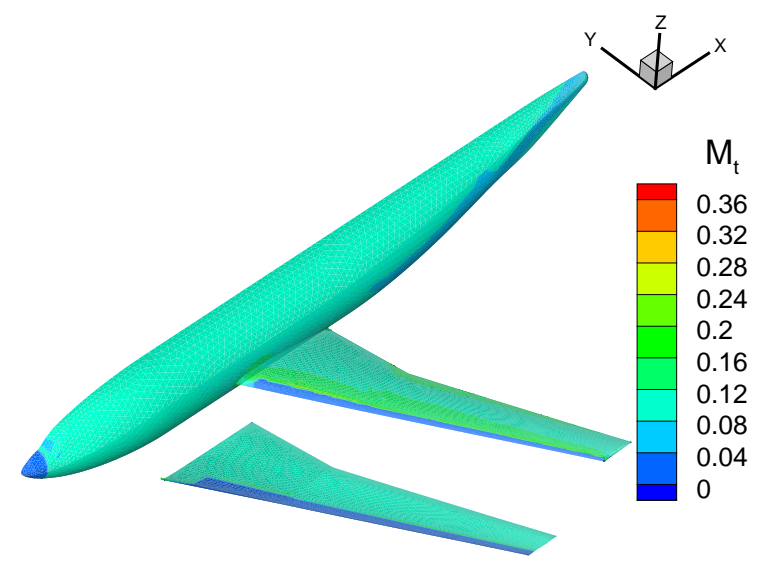

Figure 18. DLR F6 wing-fuselage solution of the computed maximum turbulence Mach number projected on the surface from the boundary layer. Computed solution for $M_{\infty}=0.75, \propto=0^{\circ}, \operatorname{Re}_{c}=3 \times 10^{6}$ is obtained by activating flow tripping at various axial locations on the fuselage and lower and upper wing surfaces. A low freestream turbulence level $\left(\mathrm{k}^{*}=1 \times 10^{-8}, \mu_{t}^{*}=0.1\right)$ is used.

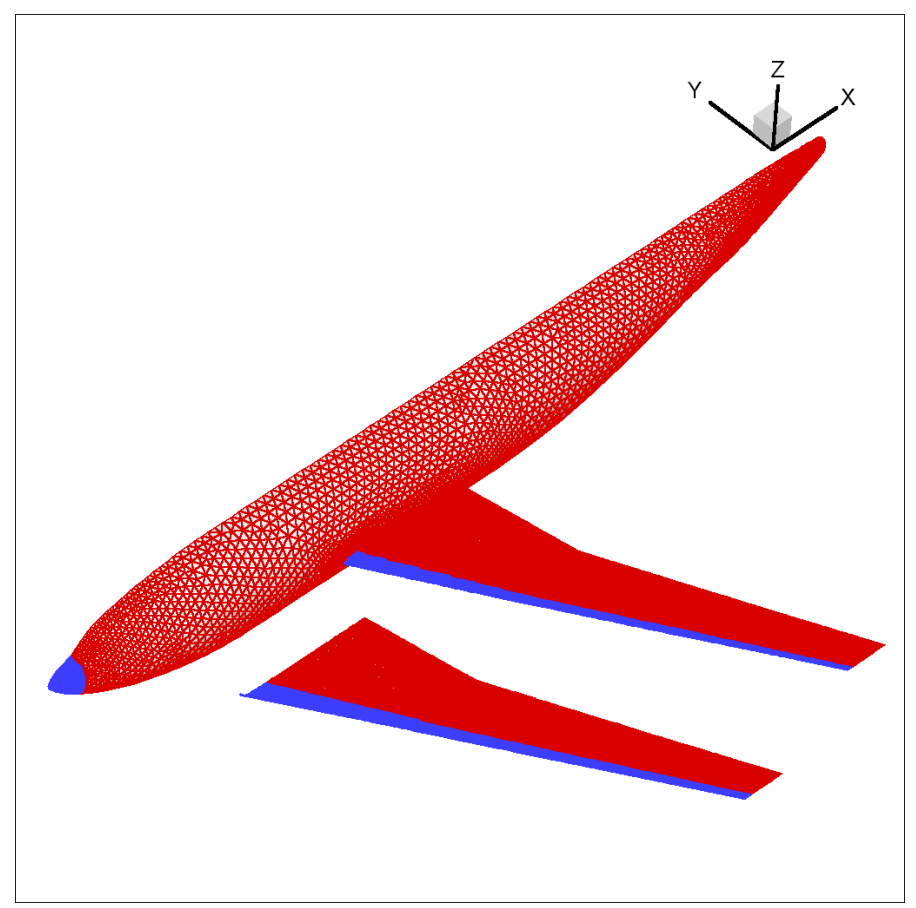

Figure 19. Schematic view of the DLR F6 wing-fuselage surface grid and a layout of the trip patches used to prescribe a laminar flow region on the configuration. 


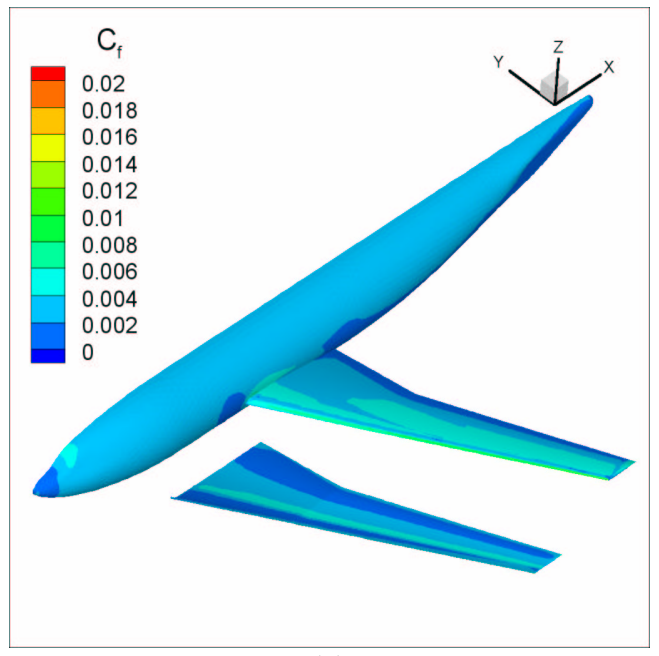

(a)

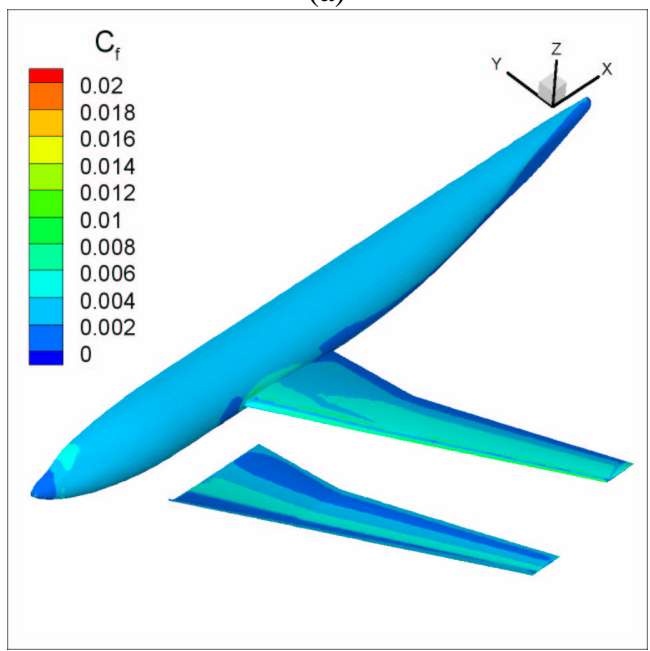

(b)

Figure 20. Local skin friction variations on the DLR F6 wing-fuselage configuration corresponding to the solutions obtained by enforcing a laminar flow region using two turbulence models (a) SA model (b) SST model. 